\title{
A Review of the Development of Nuclear Waste Treatment for China's Nuclear Power Industry
}

\author{
Yue SHU*, Zhi-ming LIU, Xian-jun LIN and Rui-zhi WANG \\ Suzhou Nuclear Power Research Institute, Suzhou, Jiangsu, China \\ E-mail: shuyue@cgnpc.com.cn
}

\begin{abstract}
The paper describes the sources and treatment of nuclear wastes generated during the production and operation of nuclear power plants, discusses the current situation and development prospects of nuclear waste treatment of China's nuclear power plants and proposes that accelerating and promoting the development of nuclear waste treatment is a practical need for China's sustainable nuclear power development as well as an important guarantee for achieving environment-friendly development of nuclear energy.
\end{abstract}

Keywords-Nuclear Power Plants; Nuclear Wastes; Nuclear Waste Treatment; Nuclear Waste Disposal; Sustainable Development

\section{INTRODUCTION TO NUCLEAR WASTE TREATMENT}

Nuclear wastes, also known as radioactive wastes, refer to any substance containing radionuclides or contaminated by them. Nuclear wastes are different from other hazardous wastes due to their high radioactivity and radiotoxicity and they are articles that are difficult to recycle and have long-term hazards, wherein nuclear wastes with a short half-life period have relatively short-term hazards and they are easy for treatment, but nuclear wastes with a long half-life period will cause long-term hazards and they are difficult for treatment. The international community has been paying special attention to how to treat and dispose of nuclear wastes in a safe manner, which is the last part (also known as back end) of nuclear cycle as well as the key to determine whether the nuclear power industry and the peaceful use of nuclear energy can achieve sustainable development.

\section{A. Classification of Nuclear Wastes}

Nuclear wastes have a wide range of sources and different shapes, composition and features. For ease of management, they are divided into several categories by physical state, radioactivity level and half-life period of radionuclides contained, etc.:

(1) According to the different physical states, nuclear wastes can be divided into solid nuclear wastes, liquid nuclear wastes and gaseous nuclear wastes.

(2) According to the different levels of radioactivity, nuclear wastes can be divided into high level wastes (HLW), intermediate level wastes (ILW) and low level wastes (LLW).

(3) According to half-life, radionuclides are divided into long-lived (or long half-life) radionuelides, intermediate-lived (or intermediate half-life) radionuelides and short-lived (or short half-life) radionuelides.

\section{B. Sources of Nuclear Wastes in Nuclear Power Plants}

Nuclear wastes can be formed in the major parts of nuclear fuel cycle and decommissioning of nuclear facilities and all sectors using radioactive materials (such as isotope production, application, etc.), and nuclear tests, nuclear research and application also generates some nuclear wastes. That is, nuclear wastes are from the technology system or sectors of nuclear fuel cycle and non-nuclear fuel cycle. The paper focuses on nuclear wastes that are generated in the production and operation of nuclear power plants.

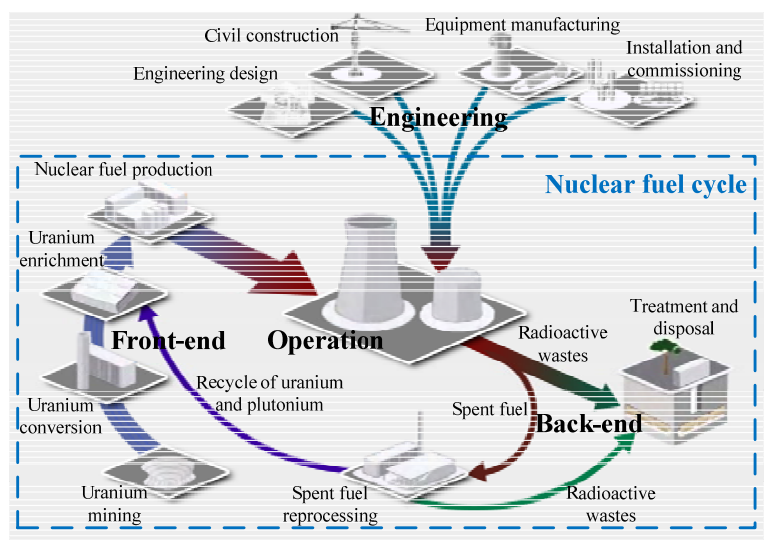

Figure 1. A Schematic Diagram of Nuclear Power Industry Chain and Nuclear Fuel Cycle

For nuclear power plants, as shown in Figure 1, nuclear wastes are generated mainly from the operation of nuclear power plants and reprocessing of spent fuel.

(1) Nuclear wastes generated in the operation of nuclear power plants

Liquid nuclear wastes and solid nuclear wastes with fission nuclides as the main composition will be produced during the operation of nuclear reactors. Among them, liquid nuclear wastes mainly come from circulating cooling water; solid nuclear wastes mainly come from cooling and purification system, spent ion exchange resins of waste water purification system, waste filter cartridge, dry residue after evaporation of liquid wastes, reactor internals material activation (cladding materials, control rods, etc.), waste instrument probe and parts, etc., wherein reactor internals are HLW. Overall, the contamination treatment equipment, 
detection equipment, chemical water purification system, ion exchange resins, waste water and appliances for labor protection of nuclear power plants, etc., are all belong to ILW and LLW categories. fuel

(2) Nuclear wastes generated in the reprocessing of spent

The irradiated nuclear fuel that could no longer be used in nuclear reactors is called spent fuel. Currently, there are two main ways to treat spent fuel internationally (Figure 2): first is once-through, namely sending spent fuel after cooling and packaging as wastes into deep geological layers for disposal or long-term storage; second is reprocessing and recycling. Since most of the compositions of spent fuel have recycling value, reprocessing of spent fuel is to extract uranium, plutonium and other elements from spent fuel and using them to continue to manufacture nuclear fuel elements. The main processes of reprocessing are various chemical processes. After most of the compositions are recovered, a large amount of ILWs and LLWs as well as a small amount of HLWs will be generated. Finally, these non-recyclable wastes will be sent into deep geological layers for disposal after solidification. Most countries developing nuclear power in the world adopt the latter approach, including China.

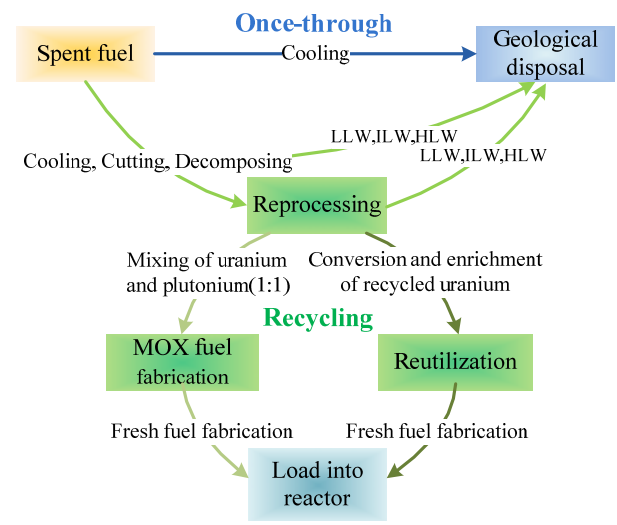

Figure 2. Two Ways to Treat Spent Fuel

\section{Treatment of Nuclear Wastes in Nuclear Power Plants}

According to the World Nuclear Association (WNA), $97 \%$ of the nuclear wastes generated by a nuclear power plant are ILWs and LLWs and the other 3\% are HLWs. ILWs and LLWs have relatively low hazards, but HLWs contain a variety of high radioelements that are extremely harmful to human health. Therefore the treatment technology and disposal strategies for ILWs and LLWs are different from those of HLWs.

(1) ILWs and LLWs

In China, the disposal of ILWs and LLWs should be in compliance with national standards and International Atomic Energy Agency (IAEA) requirements, i.e. both solid and liquid nuclear wastes should be solidified and then put in stainless steel drums and stored in interim storage vaults in nuclear power plants for 5 years, followed by transported to disposal sites and buried safely in the shallow geological disposal depository 100 300m underground.

(2) HLWs

Spent fuel and HLWs of nuclear power plants are the sectors mostly attracting people's attention in nuclear waste treatment and disposal. In the closed nuclear fuel cycle used in China, spent fuel needs to be transported to a reprocessing plant for reprocessing after stored in spent fuel pools of nuclear power plants for 5 to 10 years. The small amount of HLWs generated during reprocessing could be no longer utilized and should be made into vitrified solid through vitrification and kept in HLW disposal sites after a period of storage.

According to the research by OECD-NEA (Nuclear Energy Agency), currently, the best treatment for HLWs is storage in deep geological depository. In China, storing high-level radioactive vitrified solid by means of deep geological storage is planned, that is, choosing the sites that meet hydrological, geological and other conditions and storing high-level radioactive vitreous solid 500 1,000m below the ground, which requires long-term safety of more than 10,000 years.

\section{Status Of NuClear WAste TREATMENT IN CHINA'S NUCLEAR POWER PLANTS}

With the large-scale development of nuclear power in China, the contradiction between the rapid growth of nuclear power capacity and nuclear waste treatment and disposal at the back-end of nuclear fuel cycle has gradually appeared.

\section{A. Nuclear Waste Storage in Nuclear Power Plants}

(1) Spent fuel storage pools are to be full

For the on-site storage of spent fuel, we take Daya Bay Nuclear Power Plant, China's earliest 1000 MWe nuclear power plant that was put into commercial operation, as an example. Daya Bay Nuclear Power Plant has been operated for more than 20 years since its commercial operation in 1994. The spent pools of Daya Bay Nuclear Power Plant that are used to store spent fuel has been full after 20+ years, so newly generated spent fuel can only be stored in other pools in the same site. Tianwan Nuclear Power Plant, another 1000 MWe nuclear power base that was also put into operation earlier, faced the similar problem. The spent fuel pools of Unit 1 and 2 for Tianwan Nuclear Power Plant, which were put into operation in 2007, are expected to reach the upper storage limit after the 9th refueling outage in 2016.

Therefore, at present, in Daya Bay and Tianwan nuclear power bases, although the capacity of the spent fuel pools can still meet the immediate needs and the pools can continue to store newly generated spent fuels, the storage time of the earliest spent fuel has exceeded expectations, and in the long run, before large-scale commercial reprocessing plants are put into operation, there is still the risk that new spent fuels have nowhere to go.

(2) Temporary storages for intermediate level and low level solid wastes have been full and in extended service

Take China's first 300 MWe commercial nuclear power plant Qinshan I as an example of temporary storage of nuclear wastes in nuclear power plants. According to an 
estimate of Qinshan Nuclear Power Joint Venture Company in early 2000, the year 2015 would be the "Doomsday" for full capacity of the temporary storage for intermediate level and low level solid wastes with the annual output of intermediate level and low level solid wastes would exceed $1,000 \mathrm{~m}^{3}$. However, the data from Nuclear and Radiation Safety Center under the Ministry of Environmental Protection in 2010 brought the full capacity time in advance to 2012. For nuclear power plants, once they don't have enough space to place radioactive wastes, the units could only be shut down. With the accumulated running time of China's nuclear power bases that were put into operation early, such as Daya Bay, Qinshan, Tianwan, etc., the contradiction between the generation and accumulation of intermediate level and low level solid wastes and the capacity of on-site temporary storages has become increasingly prominent, and some ILWs and LLWs have already exceeded the 5-year temporary period prescribed by the State Council, but they have to continue to be temporarily stored in the nuclear power plants because there aren't other places for storage.

\section{B. Construction of Nuclear Waste Disposal Sites}

(1) Site selection for ILW and LLW disposal sites has been suspended for years

Compared with the difficulties encountered by temporary storages, domestic LLW and LLW disposal sites are in a even more difficult situation. China provides in Regulations for Radioactive Waste Management that ILW and LLW should be disposed of according to the "regional disposal" policy. In this regard, China originally planned to build 5 regional disposal sites in the southwest, northwest, east, south, north of China and ILW and LLW generated in nuclear power plants would be transferred to regional disposal sites for final disposal after temporary storage in the plants within 5 years.

However, there are only two completed ILW and LLW disposal sites in China at the present time: Beilong Disposal Site near Guangdong Daya Bay and Northwest Disposal Site in Gansu 404 Factory. Besides, Feifeng Mountain Disposal Site (the southwest disposal site) in Sichuan is under construction. Among them, Beilong Disposal Site is adjacent to Daya Bay Nuclear Power Base and is only $5 \mathrm{~km}$ away from Daya Bay Nuclear Power Plant. Currently, it only accepts and disposes of ILWs and LLWs generated from Daya Bay and Ling Ao Nuclear Power Plants. In other words, Beilong Site is actually not the disposal site in the south of China mentioned above.

In China, the selected sites for ILW and LLW disposal sites are not necessarily the most concentrated areas of nuclear power plants, so local governments only have obligations but no benefits, resulting in a deadlock over regional disposal. For already completed disposal sites, provinces with disposal sites are not willing to accept ILWs and LLWs from other provinces. The Northwest Disposal Site in 404 Factory currently only accepts some ILWs and LLWs generated by military facilities and it does not accept ILWs and LLWs from commercial nuclear power plants. As for Feifeng Mountain Disposal Site in Sichuan that is under construction, there are military facilities in its location already, so there is little resistance to the new disposal site. However, it also plans only to accept ILWs and LLWs from the nuclear power plants that have existed or may be developed in the future within the province.

(2) HLW disposal sites envisions an unforeseeable future

Due to the high risks of HLWs, irreparable losses will be caused once HLW disposal sites are inappropriately selected. Therefore the disposal sites must be selected carefully with the country's economic development arrangement, population distribution, transportation, and geological, hydrological and climatic conditions should be combined considered. Generally, HLW disposal sites around the world are built in economically backward and sparsely populated areas. According to international experience, HLW disposal sites were costly and time-consuming in construction.

According to the plan of the State Administration of Science, Technology and Industry for National Defence, three-step goals have been established for China's HLW geological disposal: the phase of lab R\&D and site selection for disposal sites (2006 2020), underground testing phase (2021 2040) and prototype disposal site demonstration and disposal site construction phase (2041 2050). The Twelfth Five-year Plan and 2020 Vision for Nuclear Safety and Radioactive Pollution Prevention and Control, which was issued by the State Council in October 2012, also proposed the goal of completing an underground HLW disposal laboratory by 2020 .

At present, Gansu Beishan site is the preferred preselected area in China for HLW disposal as well as the one with the deepest level of research and engineering. Since its first drilling in 2000, currently there are 19 holes in all, of which 8 are shallow boreholes. However, compared with the progress of other disposal sites in the world, Beishan data collection is far from enough. Some foreign disposal sites have drilled thousands of holes. Evidently, according to the current progress, the planning goal of completing the underground laboratory before 2020 is almost impossible.

In addition, controversies still exist in the industry over whether to start laboratory construction in Beishan as soon as possible and determine it as the final disposal site. Opponents believe that Beishan site has granite rocks and sites with clay rocks should be reselected to compare with it before making a decision. Conclusions should not be drawn too early; in addition, the disposal site will be used to store vitreous, from the perspective of back-end nuclear cycle chain, vitreous will not be generated in huge quantities before reprocessing plant and vitrification project are completed, so disposal site construction is not urgent and it should be considered slowly and carefully. However, proponents believe that if we reason backward according to the goal of completing the underground lab by 2020, taking into account the lab construction period, the lab construction should begin as soon as possible in Beishan site. Even if a more appropriate site is selected in the future, the final disposal site can also be built in other site. They are not contradictory. 


\section{Nuclear Waste Treatment Prospects of CHINA's NUCLEAR POWER PLANTS}

\section{A. China's Nuclear Waste Disposal Market Capacity}

According to Article 41 of China's Environmental Protection Law that started implementation since January 1, 2015, "Pollution prevention facilities in construction projects should be simultaneously designed, constructed and put into use with the main project”. Nuclear waste disposal sites are pollution prevention facilities. That is, if a new nuclear power plant is built, the construction of nuclear waste disposal sites and the main nuclear power project must comply with the above "three-simultaneous" system. This also means that the owners of nuclear power plants have only two choices: one is to construct supporting nuclear waste disposal sites by themselves and the other is to sign an agreement on nuclear waste receiving and disposal with disposal sites in the region.

At present, in the mainland China, the provinces Guangdong, Guangxi, Liaoning, Fujian, Hainan, Zhejiang, Jiangsu and Shandong have nuclear power plants in operation or under construction. The nuclear power projects of the above provinces are all located in coastal sites. At present, the coastal sites that comply with nuclear power plant siting requirement have been depleted and the space for continuous development is limited, so nuclear power development is bound to expand to other provinces in the future. According to public information, currently 11 provinces and municipalities are proposing to develop nuclear power, including Heilongjiang, Jilin, Anhui, Hunan, Hubei, Jiangxi, Sichuan, Chongqing, Henan, Hebei and Guizhou.

If the deadlock of regional disposal could be broken successfully, China will have at least 5 ILW and LLW disposal sites in the future. However, if the regional disposal policy ultimately cannot be effectively implemented, the above-mentioned provinces with existing or proposed nuclear power projects should build supporting nuclear waste disposal sites within the provinces by themselves, which means that China's nuclear waste disposal sites will reach a maximum of about 20 in the future plus Gansu Beishan HLW Disposal Site.

\section{B. China's Nuclear Waste Disposal Market Size}

As of the end of June 2015, 25 nuclear power units were put into operation with an installed capacity of $23.545 \mathrm{GW}$ in China. According to IAEA, the generation of radioactive solid wastes from LWR nuclear power plants is about $550 \mathrm{~m}^{3} /(\mathrm{GW} \cdot \mathrm{a})$. Based on this, at present, the annual generation of nuclear wastes of China's operating nuclear power plants would be a total of approximately 13,000 $\mathrm{m}^{3}$.

According to the objectives stated in the Medium-term and Long-term Nuclear Power Development Plan (2011-2020), the installed capacity of China's nuclear power in operation and under construction will reach $58 \mathrm{GW}$ and $30 \mathrm{GW}$ respectively by 2020 . According to the above calculation, the annual generation of nuclear wastes from China's nuclear power plants in operation would be up to about $32,000 \mathrm{~m}^{3}$ annually 5 years later and about $48,500 \mathrm{~m}^{3}$ annually 10 years later.

According to public information, there are temporarily no data about China's current cost on nuclear waste disposal. Referring to the nuclear waste disposal fee standards of the United States, namely \$30,000 50,000 (about RMB 200,000 350,000) for each unit volume, the market size of China's nuclear waste disposal would reach RMB 6.5 9.5 billion per year in 2020 and RMB 10 14.5 billion per year in 2025. The above data has not covered the costs associated with the construction and operation of reprocessing plants and waste disposal sites, etc.

\section{CONCLUSION}

In the background of energy mix restructuring and promotion of energy conservation and emission reduction, China has proposed a huge nuclear power development plan and the scale of nuclear power under construction ranks first in the world. The back-end development of nuclear fuel cycle is closely related to the development of nuclear power and they are interdependent and mutually matching, so accelerating the development of nuclear waste disposal industry is in line with China's nuclear power development policy, and nuclear waste disposal has huge demands and broad market prospects. However, nuclear waste disposal is also a weak part in China's nuclear power industry and would become an important factor restricting China's nuclear power development as well as a potential risk for ecological environment.

China has determined the "closed fuel cycle" policy since the beginning of nuclear power development in the early 1980s. The implementation of closed-cycle has important strategic significance for improving the utilization of uranium resources and achieving environmentally friendly nuclear energy development. As an important part of the closed nuclear fuel cycle system, treatment and final disposal of nuclear waste is an important foundation and protection for China's safe and orderly development of nuclear energy. Therefore, actively promoting the synchronous and balanced development of nuclear waste disposal and nuclear power construction is a strategic alternative for China to establish a complete, advanced and self-reliant nuclear fuel cycle system, a practical need of China's sustainable nuclear power development and an important guarantee for achieving environment-friendly development of nuclear energy.

\section{REFERENCES}

[1] Luo Shanggeng. Introduction to Radioactive Waste[M]. Beijing: Atomic Energy Press, 2003.

[2] IAEA.Classification of radioactive waste[R].IAEA Safety Series No.111-G-1,Vienna: IAEA,1994.

[3] IAEA.The Principles of radioactive waste management[R].Safety Series No. 115. Vienna: IAEA,1995.

[4] Hao Qing, Liu Changliang, Du Zibing. Research on Nuclear Waste Treatment and Management Strategies[J]. Science 2012, 11, 159-160.

[5] Huang Yawen. Discussion of Several Problems in ILW and LLW Disposal in China[J]. Radiation Protection, 1994, 14(1): 33-38. 
[6] Shen Zhenyao. Method to Treatment and Disposal HLW[J]. Radiation Protection Bulletin, 2002, 22(1): 37-39. 